\begin{tabular}{|c|l|}
\hline Title & $\begin{array}{l}\text { Surface passivation of GaN and GaN A IGaN heterostructures by dielectric films and its application to insul ated-gate } \\
\text { heterostructure transi stors }\end{array}$ \\
\hline Author(s) & Hashizume, Tamotsu; Ootomo, Shinya; Inagaki, Takanori; Hasegawa, Hideki \\
\hline Citation & $\begin{array}{l}\text { Journal of V acuum Science \& Technology B: Microelectronics and Nanometer Structures, 21(4), 1828 1838 } \\
\text { https://doi.org/10.1116/1.1585077 }\end{array}$ \\
\hline Issue Date & 2003-08-05 \\
\hline Doc URL & http://hdl.handle.net/2115/5804 \\
\hline Type & article \\
\hline File Information & JV STB21-4.pdf \\
\hline
\end{tabular}

Instructions for use 


\title{
Surface passivation of GaN and GaN/AIGaN heterostructures by dielectric films and its application to insulated-gate heterostructure transistors
}

\author{
Tamotsu Hashizume, ${ }^{\text {a) }}$ Shinya Ootomo, Takanori Inagaki, and Hideki Hasegawa \\ Research Center for Integrated Quantum Electronics (RCIQE), Hokkaido University, \\ Sapporo 060-8628, Japan
}

(Received 19 January 2003; accepted 22 March 2003; published 5 August 2003)

\begin{abstract}
We have systematically investigated effects of plasma processing, formation of Si-based dielectrics, and formation of a thin $\mathrm{Al}_{2} \mathrm{O}_{3}$ film on the chemical and electronic properties of $\mathrm{GaN}$ and $\mathrm{GaN}$ / AlGaN heterostructure surfaces. The surface treatment in $\mathrm{H}_{2}$-plasma excited by electron-cyclotron-resonance (ECR) source, produced nitrogen-vacancy-related defect levels at GaN and $\mathrm{AlGaN}$ surfaces, while the ECR- $\mathrm{N}_{2}$-plasma treatment improved electronic properties of the surfaces. The deposition of a $\mathrm{SiO}_{2}$ film on $\mathrm{GaN}$ and $\mathrm{AlGaN}$ surfaces was found to induce high-density interface states, due to unexpected and uncontrollable oxidation reactions on the surfaces during the deposition process. In comparison, the $\mathrm{SiN}_{x} / \mathrm{GaN}$ passivation structure prepared by ECR-plasma assisted chemical vapor deposition showed good interface properties with the minimum $D_{\text {it }}$ value of $1 \times 10^{11} \mathrm{~cm}^{-2} \mathrm{eV}^{-1}$. However, excess leakage currents governed by FowlerNordheim tunneling were observed in the $\mathrm{SiN}_{x} / \mathrm{Al}_{0.3} \mathrm{Ga}_{0.7} \mathrm{~N}$ structure, due to a relatively small conduction band offset of $0.7 \mathrm{eV}$ between $\mathrm{SiN}_{x}$ and $\mathrm{Al}_{0.3} \mathrm{Ga}_{0.7} \mathrm{~N}$. A novel $\mathrm{Al}_{2} \mathrm{O}_{3}$-based passivation structure was proposed and fabricated by molecular beam deposition of $\mathrm{Al}$ and subsequent ECR $\mathrm{O}_{2}$-plasma oxidation. In situ x-ray photoelectron spectroscopy showed successful formation of the $\mathrm{Al}_{2} \mathrm{O}_{3}$ layer with a thickness of $3.5 \mathrm{~nm}$ and a large conduction band offset of $2.1 \mathrm{eV}$ between $\mathrm{Al}_{2} \mathrm{O}_{3}$ and $\mathrm{A}_{0.3} \mathrm{Ga}_{0.7} \mathrm{~N}$. The GaN/AlGaN insulated-gate heterostructure field-effect transistors (IG HFETs) having the $\mathrm{Al}_{2} \mathrm{O}_{3}$-based passivation structure showed a good gate control of drain currents up to $V_{\mathrm{GS}}=+3 \mathrm{~V}$ and achieved drain saturation current of $0.8 \mathrm{~A} / \mathrm{mm}$. The observed maximum $g_{m}$ value is $120 \mathrm{mS} / \mathrm{mm}$. No current collapse was observed in the $\mathrm{Al}_{2} \mathrm{O}_{3}$ IG HFETs, indicating a remarkable advantage of the present $\mathrm{Al}_{2} \mathrm{O}_{3}$-based passivation structure. () 2003 American Vacuum Society. [DOI: $10.1116 / 1.1585077$ ]
\end{abstract}

\section{INTRODUCTION}

Recent progress in high-power/high-frequency field-effect transistors (FETs) based on GaN and its related heterostructures has demonstrated that they are key devices for nextgeneration high-density communication systems. However, these devices still have surface/interface-related problems, including collapse in drain current, ${ }^{1}$ excess gate leakage, ${ }^{2,3}$ and aging of Schottky contacts. ${ }^{4}$ Furthermore, the device processing involves various kinds of surface treatments and junction formation steps, which may introduce defects on the processed $\mathrm{GaN}$ and $\mathrm{AlGaN}$ surfaces. A surface passivation process consisting of a suitable surface treatment and the formation of the insulated gate (IG) and passivation structure can solve these problems. In this regard, understanding and controlling surface properties of $\mathrm{GaN}$ and $\mathrm{GaN}$-based heterostructures are of utmost importance.

For a prepassivation process, it is important to investigate cleaning processes for $\mathrm{GaN}$ and $\mathrm{AlGaN}$ surfaces. However, there are a few reports on the processed surfaces such as chemically treated surfaces, plasma-treated surfaces, etc. King et al. ${ }^{5}$ and Hartlieb et al. ${ }^{6}$ have investigated wet and dry cleaning processes for $\mathrm{GaN}$ and AlN surfaces, and proposed the ammonia-based high-temperature chemical vapor process. Our group has investigated correlation between

${ }^{a}$ Electronic mail: hashi@rciqe.hokudai.ac.jp chemical and electronic properties of $\mathrm{GaN}$ and $\mathrm{AlGaN}$ surfaces after various types of surface treatments, ${ }^{7-9}$ and reported that the surface treatment using $\mathrm{N}_{2}$ plasma excited by electron-cyclotron-resonance (ECR) source was very effective in improving the electronic properties of $\mathrm{GaN}$ and AlGaN surfaces. ${ }^{9}$

For the final stage of surface passivation and insulated gate structures, the use of dielectric films is indispensable. In this regard, there have been several studies on the properties of metal-insulator-semiconductor (MIS) structures using $\mathrm{GaN}$ and the surface passivation of GaN/AlGaN heterostructure field effect transistors (HFETs). A pioneering work on the GaN MISFET using a $\operatorname{SiN}_{x}$ gate was reported by Binari et al. ${ }^{10}$ They deposited a $\mathrm{SiN}_{x}$ film on $\mathrm{GaN}$ by radiofrequency (rf) plasma enhanced chemical vapor deposition. However, the devices displayed low transconductance $\left(g_{m}\right)$ due to high-density interface states. Kawai and co-workers ${ }^{11}$ have demonstrated good dc performance of the GaN IG FET using an epitaxial AlN layer as a gate dielectric. However, it is very difficult to suppress the leakage current through AlN because of the difficulty of growing high-quality AlN films. ${ }^{12}$ Hashizume, Nakasaki and Hasegawa ${ }^{13,14}$ demonstrated for the first time that good interface properties can be realized in $\mathrm{SiN}_{x} / \mathrm{GaN}$ passivation structures prepared by the ECR- $\mathrm{N}_{2}$ plasma treatment and ECR-assisted chemical vapor deposition (ECR CVD). Thereafter, $\mathrm{SiN}_{x}$-based surface passivation 
TABLE I. Values of band gap, dielectric constant, and breakdown field for $\mathrm{Al}_{0.3} \mathrm{Ga}_{0.7} \mathrm{~N}$ and some dielectrics.

\begin{tabular}{|c|c|c|c|}
\hline & $E_{G}(\mathrm{eV})$ & $\varepsilon_{S}$ & $\begin{array}{c}\text { Breakdown } \\
\text { field }(\mathrm{MV} / \mathrm{cm})\end{array}$ \\
\hline $\mathrm{Al}_{0.3} \mathrm{Ga}_{0.7} \mathrm{~N}$ & 4.1 & $9.0-9.5$ & $>5$ \\
\hline $\mathrm{SiO}_{2}$ & 9 & 3.9 & 10 \\
\hline $\mathrm{Si}_{3} \mathrm{~N}_{4}$ & 5.0 & 7 & 10 \\
\hline $\mathrm{Ga}_{2} \mathrm{O}_{3}$ & 4.5 & 10 & $1-3$ \\
\hline $\mathrm{Ta}_{2} \mathrm{O}_{5}$ & 5 & $10-20$ & $>10$ \\
\hline $\mathrm{MgO}$ & 8 & $8-9$ & 5 \\
\hline AlN & 6.2 & 8.5 & $10-15$ \\
\hline $\mathrm{Al}_{2} \mathrm{O}_{3}$ & $7-9$ & $9-10$ & $>10$ \\
\hline
\end{tabular}

structures have been applied to the GaN/AlGaN HFETs. ${ }^{115-19}$ Green et al. ${ }^{15}$ and Lee et al. ${ }^{16}$ reported the improvement of rf-power performance in the GaN/AlGaN HFETs. The reduction of current collapse was reported in the $\mathrm{SiN}_{x}$ IG GaN/AlGaN HFET, ${ }^{17}$ or the $\mathrm{SiN}_{x}$-passivated GaN/ AlGaN HFETs. ${ }^{1,18,19}$

Other dielectrics such as $\mathrm{SiO}_{2}, \mathrm{Ga}_{2} \mathrm{O}_{3}, \mathrm{MgO}$ and the native oxide of $\mathrm{AlGaN}$ have also been applied to the surface passivation of $\mathrm{GaN}$ and $\mathrm{AlGaN}$ surfaces. Therrien et al. ${ }^{20}$ reported the passivation process including separate plasma oxidation of $\mathrm{GaN}$ and the deposition of thick $\mathrm{SiO}_{2}$ film using remote plasma. Hong et al. ${ }^{21}$ demonstrated that the $\mathrm{Ga}_{2} \mathrm{O}_{3}\left(\mathrm{Gd}_{2} \mathrm{O}_{3}\right) / \mathrm{GaN}$ system fabricated by molecular beam epitaxy (MBE) and electron beam evaporation showed low interface state densities. Gaffey et $\mathrm{al}^{22}{ }^{22}$ reported good interface properties of the $\mathrm{SiO}_{2} / \mathrm{GaN}$ structures prepared by jet vapor deposition. Inoue and co-workers ${ }^{23}$ fabricated the IG $\mathrm{AlGaN} / \mathrm{GaN}$ HFET using native oxide of $\mathrm{AlGaN}$ itself formed by thermal oxidation at $900{ }^{\circ} \mathrm{C}$. Luo et al..$^{24}$ reported the passivation effects of the MBE-grown $\mathrm{MgO}$ films on the AlGaN/GaN HFETs.

In spite of these efforts, properties of insulatorsemiconductor interfaces of $\mathrm{GaN}$ and $\mathrm{AlGaN}$ are not fully understood and successful surface passivation of $\mathrm{GaN} /$ AlGaN HFETs is not achieved.

In this article, we present a systematic investigation on effects of ECR-plasma processing and $\mathrm{SiO}_{2}$ - and $\mathrm{SiN}_{x}$-based passivation on chemical and electrical properties of $\mathrm{GaN}$ and $\mathrm{AlGaN}$ surfaces. We used the ECR-plasma process for the surface treatments and the deposition of dielectrics, because it is a remote plasma process and it utilizes ions with low energies of 10 to several tens of eV. It is also shown that an $\mathrm{Al}_{2} \mathrm{O}_{3}$-based surface passivation structure drastically improves the electrical properties of GaN/AlGaN HFETs. Table I summarizes values of band gap, dielectric constant, and breakdown field for dielectrics previously applied or to be applicable to surface passivation of $\mathrm{AlGaN}$. Those for $\mathrm{Al}_{0.3} \mathrm{Ga}_{0.7} \mathrm{~N}$ are also listed. Among them, $\mathrm{Al}_{2} \mathrm{O}_{3}$ is very attractive as an insulated gate for GaN/AlGaN HFETs because it has larger bandgap than that of $\mathrm{Al}_{0.3} \mathrm{Ga}_{0.7} \mathrm{~N}$, a high dielectric constant and a high breakdown electric field. Furthermore, $\mathrm{Al}_{2} \mathrm{O}_{3}$ is one of the native oxides of $\mathrm{AlGaN}$. Thus, we developed the formation process of a thin $\mathrm{Al}_{2} \mathrm{O}_{3}$ layer on

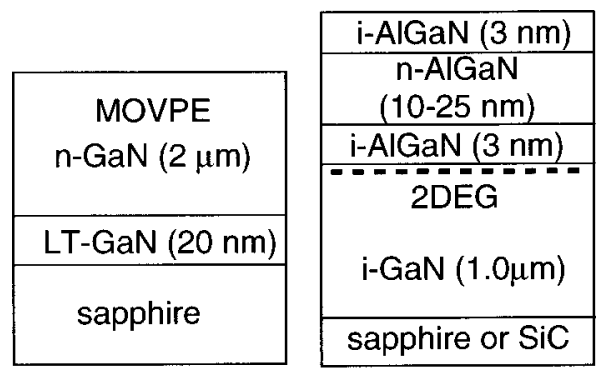

(a)

(b)

FIG. 1. Schematic illustrations of $\mathrm{GaN}$ and $\mathrm{GaN} / \mathrm{AlGaN}$ heterostructure sample structures.

AlGaN by a combination of molecular beam deposition of $\mathrm{Al}$ and the subsequent ECR- $\mathrm{O}_{2}$ plasma oxidation.

\section{EXPERIMENT}

\section{A. GaN and GaN/AIGaN sample structures}

Figure 1 shows schematic illustrations of $\mathrm{GaN}$ and $\mathrm{GaN} /$ AlGaN sample structures. High-quality epitaxial GaN wafers grown on sapphire substrates by metal organic vapor phase epitaxy (MOVPE) were used in this study. A buffer GaN layer (LT-GaN) was grown at low temperatures (500$550{ }^{\circ} \mathrm{C}$ ) followed by the growth of a Si-doped GaN layer using $\mathrm{SiH}_{4}$ as a dopant source at $1000^{\circ} \mathrm{C}$. Typical values of electron concentration and mobility of the Si-doped layer at room temperature (RT) is $2 \times 10^{17} \mathrm{~cm}^{-3}$ and $500 \mathrm{~cm}^{2} / \mathrm{V} \mathrm{s}$, respectively.

The heterostructure samples grown by MOVPE consist of undoped $\mathrm{GaN}$, undoped $\mathrm{Al}_{x} \mathrm{Ga}_{1-x} \mathrm{~N}$, Si-doped $\mathrm{Al}_{x} \mathrm{Ga}_{1-x} \mathrm{~N}$, and undoped $\mathrm{Al}_{x} \mathrm{Ga}_{1-x} \mathrm{~N}$, as shown in Fig. 1(b). The Al content, $x$, ranged from 0.25 to 0.30 . The samples showed clear Shuvnikov-de Haas oscillation in magnetoresistance characteristics at $2 \mathrm{~K}$, and the electron concentrations determined from the Landau plots of the oscillation were in good agreement with the values obtained by the Hall measurement at the same temperature. These results clearly indicated the existence of two-dimensional electron gas (2DEG) at the GaN/ $\mathrm{AlGaN}$ heterointerfaces. Typical values of the electron concentration and mobility of 2DEG at RT were 1.1 $\times 10^{13} \mathrm{~cm}^{-2}$ and $900 \mathrm{~cm}^{2} / \mathrm{V} \mathrm{s}$, respectively.

\section{B. Surface passivation and device fabrication processes}

The surface passivation process started from a simple wet treatment in organic solvents at $\mathrm{RT}$ and in an $\mathrm{NH}_{4} \mathrm{OH}$ solution at $50{ }^{\circ} \mathrm{C}$ for $5-10 \mathrm{~min}$. The $\mathrm{NH}_{4} \mathrm{OH}$ treatment is effective in reducing natural oxides on $\mathrm{GaN}$ and $\mathrm{AlGaN}$ surfaces. ${ }^{7,8}$

For successful surface passivation of $\mathrm{GaN}$ and $\mathrm{AlGaN}$ surfaces, in situ processing and characterization were performed in the ultra-high-vacuum (UHV) multichamber system. All the chambers are connected to each other through a UHV tunnel chamber whose base pressure is 2 $\times 10^{-10}$ Torr. 
For a pretreatment of the deposition of dielectric films, $\mathrm{GaN}$ and GaN/AlGaN surfaces were exposed to $\mathrm{N}_{2}$ plasma or $\mathrm{H}_{2}$ plasma excited by an ECR source with microwave $(2.75 \mathrm{GHz})$ power of $50 \mathrm{~W}$. The processing temperature and time were $280^{\circ} \mathrm{C}$ and $1-5 \mathrm{~min}$, respectively. The deposition of $\mathrm{SiO}_{2}$ and $\mathrm{SiN}_{x}$ was performed at $280^{\circ} \mathrm{C}$ by ECR CVD, using $\mathrm{SiH}_{4}$ and $\mathrm{N}_{2} \mathrm{O}$ as precursors for $\mathrm{SiO}_{2}$ and $\mathrm{SiH}_{4}$ and $\mathrm{N}_{2}$ for $\mathrm{SiN}_{x}$, respectively. The thickness of the deposited films ranged from 20 to $70 \mathrm{~nm}$. We obtained refractive index values of 1.47 and 1.98 for the deposited $\mathrm{SiO}_{2}$ and $\mathrm{SiN}_{x}$ films, respectively.

The device isolation was performed by an ECR-assisted reactive ion beam etching using a gas system consisting of $\mathrm{CH}_{4}, \mathrm{H}_{2}, \mathrm{Ar}$, and $\mathrm{N}_{2}$. The addition of $\mathrm{N}_{2}$ to the gas system is very effective in achieving smooth and stoichiometric GaN and AlGaN surfaces even after the etching. ${ }^{25}$ As an Ohmic contact, a Ti/Al/Ti/Au layered structure was deposited on the surfaces of $\mathrm{GaN}$ and $\mathrm{GaN} / \mathrm{AlGaN}$ followed by the annealing at $600{ }^{\circ} \mathrm{C}$ for $\mathrm{GaN}$ and $800{ }^{\circ} \mathrm{C}$ for $\mathrm{GaN} / \mathrm{AlGaN}$ for $2 \mathrm{~min}$ in $\mathrm{N}_{2}$ ambient. A Ni/Au contact was used as a Schottky gate on $\mathrm{GaN}$ and $\mathrm{AlGaN}$.

\section{Characterization methods}

The surface chemical properties of $\mathrm{GaN}$ and $\mathrm{GaN} / \mathrm{AlGaN}$ samples were characterized by $\mathrm{x}$-ray photoelectron spectroscopy (XPS). The XPS system is connected to the UHV multichamber system, thereby in situ XPS characterization of the processed $\mathrm{GaN}$ and $\mathrm{GaN} / \mathrm{AlGaN}$ surfaces is available. The XPS measurement system (Perkin Elmer PHI 1600C) consists of a spherical capacitor analyzer and a monochromated Al $K \alpha$ x-ray source $(h \nu=1486.6 \mathrm{eV})$. The binding energies of the spectra were carefully calibrated through separate measurements of $\mathrm{Cu} 2 p_{3 / 2}, \mathrm{Ag} 3 d_{5 / 2}$, and $\mathrm{Au} 4 f_{7 / 2}$ peak positions. Atomic force microscope (AFM) observation of $\mathrm{GaN}$ surfaces after various types of surface treatments was carried out using a Nanoscope II (Digital Instruments). Currentvoltage $(I-V)$ and capacitance-voltage $(C-V)$ measurements were performed using HP 4156A semiconductor parameter analyzer and HP 4192A LF impedance analyzer, respectively.

\section{RESULTS AND DISCUSSION}

\section{A. Effects of plasma processing on chemical and electronic properties of GaN and AIGaN surfaces}

Figure 2 shows XPS Ga $3 d$ and $\mathrm{Al} 2 p$ spectra obtained from the air-exposed $\mathrm{Al}_{0.25} \mathrm{Ga}_{0.75} \mathrm{~N}$ surface. Both the $\mathrm{Ga} 3 d$ and $\mathrm{Al} 2 p$ peaks showed asymmetric features with shoulders at higher binding energies. We assigned these higher peaks to $\mathrm{Ga}_{2} \mathrm{O}_{3}$ and $\mathrm{Al}_{2} \mathrm{O}_{3}$, respectively. For deconvolution of the observed spectra, we have separately determined the peak energies and linewidths of the spectra in the $\mathrm{Al}_{2} \mathrm{O}_{3}$ and $\mathrm{Ga}_{2} \mathrm{O}_{3}$ phases, using a crystalline sapphire substrate and a sample prepared by oxidizing the metallic $\mathrm{Ga}$ layer, respectively. Both spectra include large amounts of oxides. This

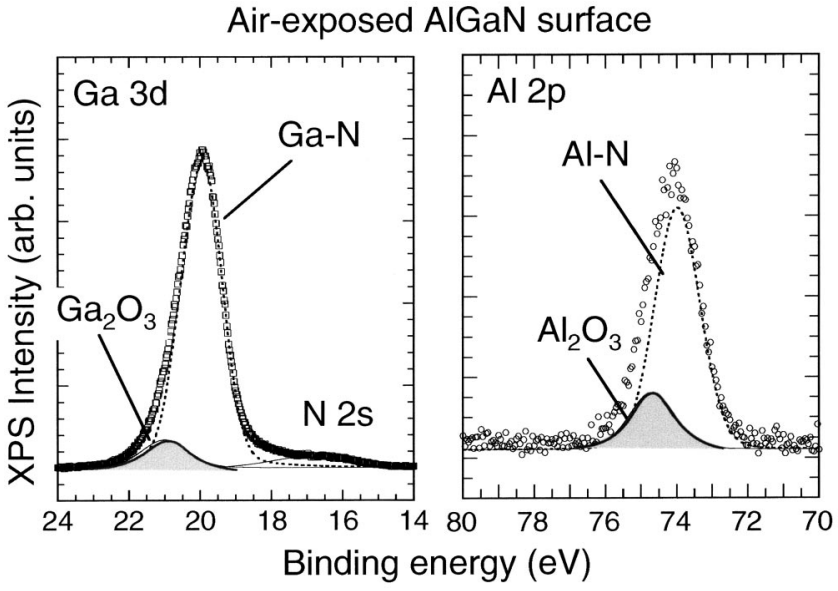

FIG. 2. XPS Ga $3 d$ and $\mathrm{Al} 2 p$ spectra obtained from the air-exposed $\mathrm{Al}_{0.25} \mathrm{Ga}_{0.75} \mathrm{~N}$ surface.

feature was responsible for the disorder in chemical composition, leading to the deterioration of surface electronic properties of $\mathrm{GaN}$ and AlGaN. ${ }^{9}$

In order to remove the disordered layer including natural oxides, the ECR-assisted plasma treatments were employed on AlGaN surfaces. Figure 3 shows the integrated XPS intensities of $\mathrm{O} 1 s$ and $\mathrm{C} 1 s$ normalized by the $\mathrm{N} 1 s$ intensity. After a wet treatment in $\mathrm{NH}_{4} \mathrm{OH}$ solution, the $\mathrm{O} 1 s$ intensity was reduced remarkably, because the $\mathrm{Ga}_{2} \mathrm{O}_{3}$ component can easily be dissolved in alkali solutions. However, the $\mathrm{C} 1 \mathrm{~s}$ intensity remained almost unchanged. Both $\mathrm{H}_{2}{ }^{-}$and $\mathrm{N}_{2}$-plasma treatments at $280{ }^{\circ} \mathrm{C}$ for $1-5 \mathrm{~min}$ are effective in removing oxides and contamination from the $\mathrm{AlGaN}$ surface, as shown in Fig. 3.

However, the effects of the surface processing on electronic properties of $\mathrm{GaN}$ and $\mathrm{AlGaN}$ surfaces are very different between $\mathrm{H}_{2}$-plasma and $\mathrm{N}_{2}$-plasma treatments. The AFM images of the plasma-treated GaN surfaces are shown in Fig. 4. The ECR-N $\mathrm{N}_{2}$ plasma treated GaN exhibited a smooth surface with a root-mean-square (rms) roughness of $0.29 \mathrm{~nm}$. The surface morphology showed the characteristic feature dominated by monolayer steps, and many of the steps were terminated by the large dark pits at the edges which could be

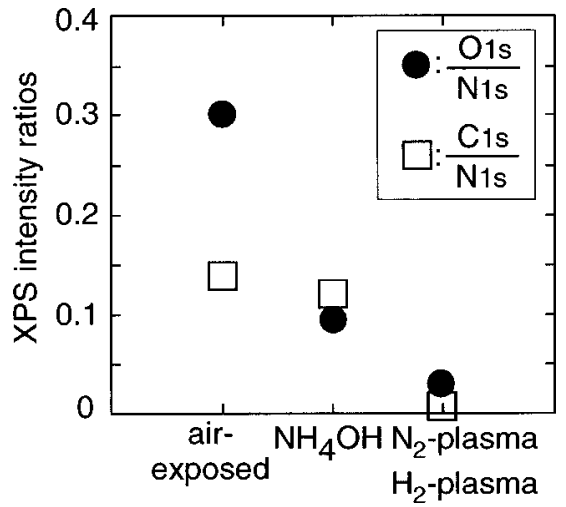

FIG. 3. Integrated XPS intensities of O $1 s$ and C $1 s$ normalized by the N $1 s$ intensity at the AlGaN surface for the different surface treatments. 


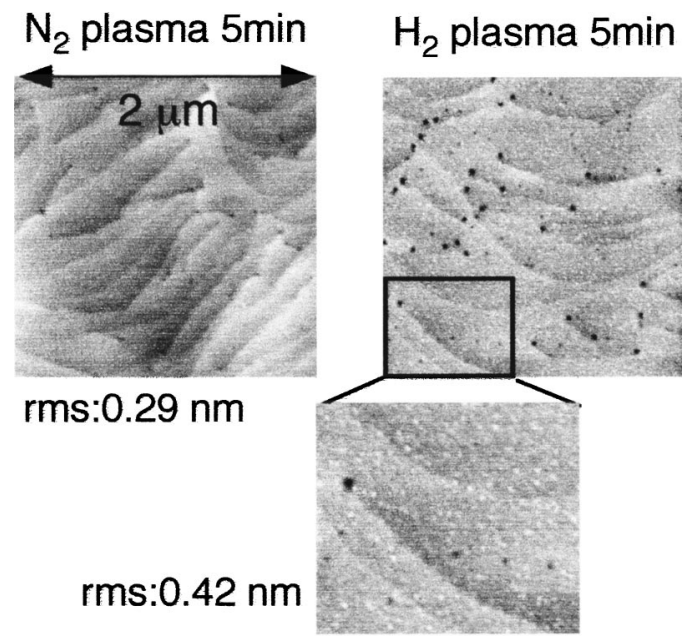

FIG. 4. AFM images of the ECR-plasma treated GaN surfaces.

correlated to the surface termination of the edge-screw mixed dislocations. ${ }^{26}$ After the $\mathrm{H}_{2}$-plasma treatment, however, the surface feature changed drastically. Large numbers of particles with diameters of about 20-30 nm were found on the treated GaN surface, as shown in the right-hand image in Fig. 4. From the XPS analysis, these particles were assigned to Ga droplets.

The surface state density $\left(D_{\mathrm{SS}}\right)$ distributions of the ECRplasma treated GaN surfaces were compared in Fig. 5. The $D_{\mathrm{SS}}$ values were determined by the $C-V$ analysis (Terman method) using $\mathrm{SiN}_{x}$-covered $\mathrm{GaN}$ samples. Except for the plasma treatments, the samples were processed under the same condition exactly. As clearly seen in Fig. 5, a localized surface level was found at approximately $E_{c}-0.5 \mathrm{eV}$ for the $\mathrm{H}_{2}$-plasma treated surfaces, while continuous $D_{\mathrm{SS}}$ distributions were observed in both the $\mathrm{N}_{2}$-plasma treated surface and control sample without plasma treatment. Thus, the $\mathrm{H}_{2}$-plasma treatment causes the formation of surface defects on the GaN surface.

In order to investigate the effects of plasma processing on the transport properties of $2 \mathrm{DEG}$ at GaN/AlGaN heterointer-

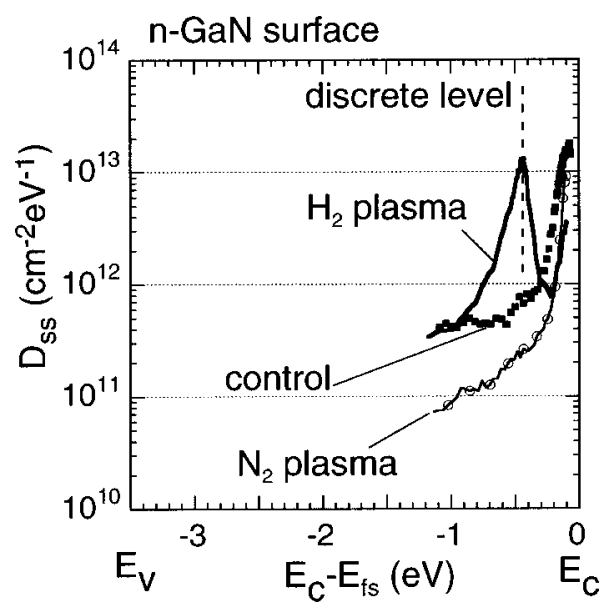

FIG. 5. Surface state density $\left(D_{\mathrm{SS}}\right)$ distributions of the ECR-plasma treated GaN surfaces.

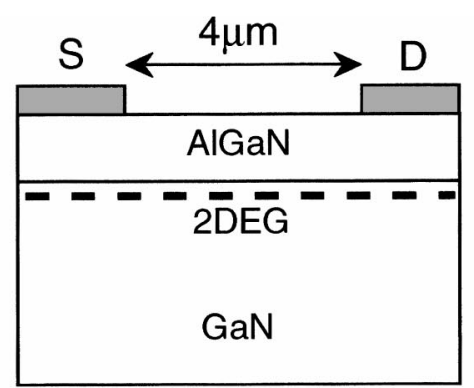

(a)

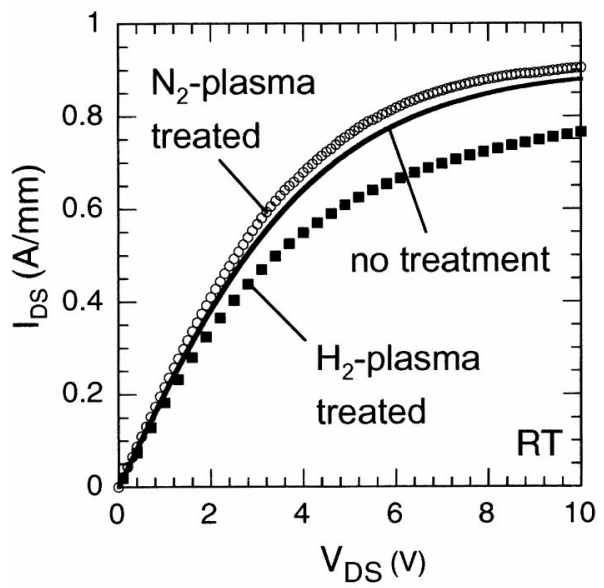

(b)

FIG. 6. (a) Gateless HFET structure and (b) current-voltage characteristics.

face, a gateless HFET structure shown in Fig. 6(a) was prepared. ${ }^{27}$ The current-voltage $\left(I_{\mathrm{DS}}-V_{\mathrm{DS}}\right)$ characteristics of the fabricated gateless HFET are shown in Fig. 6(b). We fabricated more than 100 devices on one chip of the GaN/ $\mathrm{AlGaN}$ structure before plasma treatments. After measuring the initial $I-V$ characteristics of the devices, the chip was divided into two samples: one for the $\mathrm{H}_{2}$-plasma treatment and the other for the $\mathrm{N}_{2}$-plasma treatment. After the plasma treatments, we compared the $I-V$ characteristics for the certain devices that had the same initial $I-V$ characteristics. All the devices showed a steep linear increase of current followed by current saturation. After the $\mathrm{H}_{2}$-plasma treatment for $1 \mathrm{~min}$, a large current reduction was observed. On the other hand, $\mathrm{N}_{2}$-plasma treatment slightly increased currents. The Hall measurement results showed that the change in currents after the plasma treatments was not due to change in mobility but due to the change in the 2DEG density. Additionally, the $\mathrm{H}_{2}$-plasma-treated devices exhibited serious hysteresis in dc $I-V$ curves as well as transient behavior in pulse-responses of the drain currents. ${ }^{27}$ These results indicate that the $\mathrm{H}_{2}$-plasma treatment produced high-density surface defect states on the AlGaN surface, causing various kinds of instabilities in the 2DEG transport at GaN/AlGaN interface. No such effects were observed in the $\mathrm{N}_{2}$-plasma treated devices.

Figure 7 shows the XPS core-level spectra taken from the AlGaN surfaces after the treatments in $\mathrm{H}_{2}$ plasma and $\mathrm{N}_{2}$ 


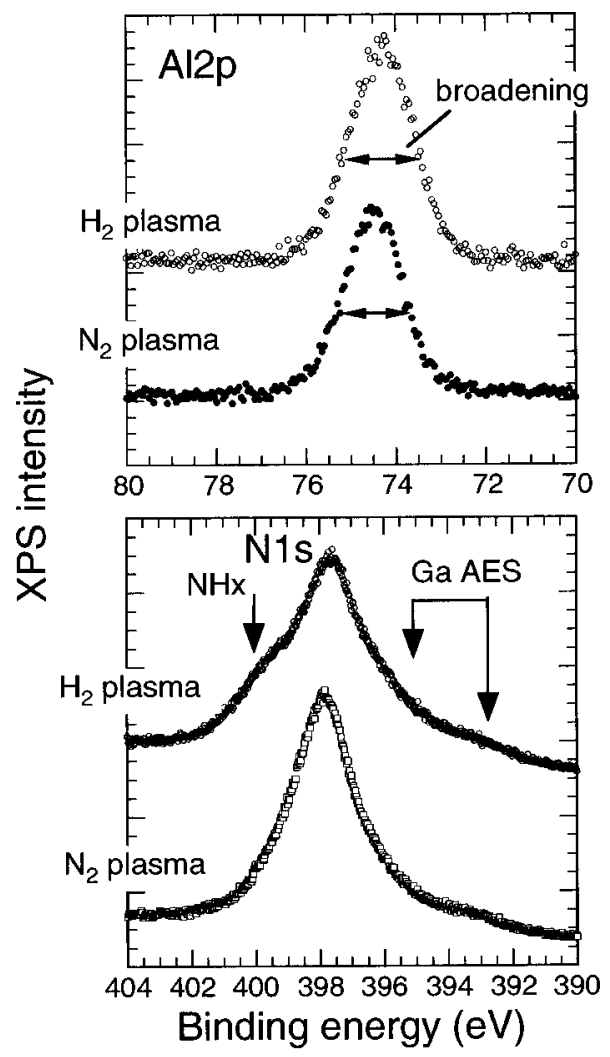

FIG. 7. XPS core-level spectra taken from the GaN/AlGaN surfaces after the treatments in ECR-excited $\mathrm{H}_{2}$ plasma and $\mathrm{N}_{2}$ plasma.

plasma for $1 \mathrm{~min}$. We detected the photoemission from the $\mathrm{AlGaN}$ surfaces using an electron escape angle of $10^{\circ}$, implying that the obtained spectra reflected information from the topmost region (within 1.0-1.5 nm). In the $\mathrm{N} 1 s$ corelevel spectrum of the $\mathrm{H}_{2}$-plasma treated sample, a clear shoulder peak appeared at around $399 \mathrm{eV}$, corresponding to the $\mathrm{N}-\mathrm{H}_{x}$ bond. ${ }^{28}$ In addition, the decrease in the peak intensity of the $\mathrm{N} 1 s$ line was observed. The V/III ratio of the AlGaN surface after the $\mathrm{H}_{2}$-plasma treatment was found to be far below unity (0.79), clearly indicating the depletion of $\mathrm{N}$ atoms at the surface. The broadening of spectrum was also observed in $\mathrm{Al} 2 p$ core level. Thus, the $\mathrm{H}_{2}$-plasma treatment for only 1 min produced disordered layer at the AlGaN surface with a highly nonstoichiometric chemical phase.

Figure 8 schematically shows a possible reaction process on $\mathrm{GaN}$ or $\mathrm{AlGaN}$ surfaces during the $\mathrm{H}_{2}$-plasma treatment. It is expected that highly active hydrogen plasma species such as hydrogen radicals react with the surface to form volatile $\mathrm{NH}_{x}$ products, as manifested as a shoulder in the XPS N $1 s$ spectrum (Fig. 7). This process led to the N depletion and left $\mathrm{Ga}$ and/or $\mathrm{Al}$ metallic clusters at the topmost $\mathrm{GaN}$ or AlGaN surfaces. Such a surface reaction process in $\mathrm{H}_{2}$ plasma caused the formation of surface disordered layer and could introduce surface defect states including $\mathrm{N}$-vacancy-related defects. Neugebauer and Van de Walle, ${ }^{29}$ and Boguslawski et al. ${ }^{30}$ have calculated energy levels of native point defects in $\mathrm{GaN}$ using the first-principle supercell method. They concluded that the simple N-vacancy cre-

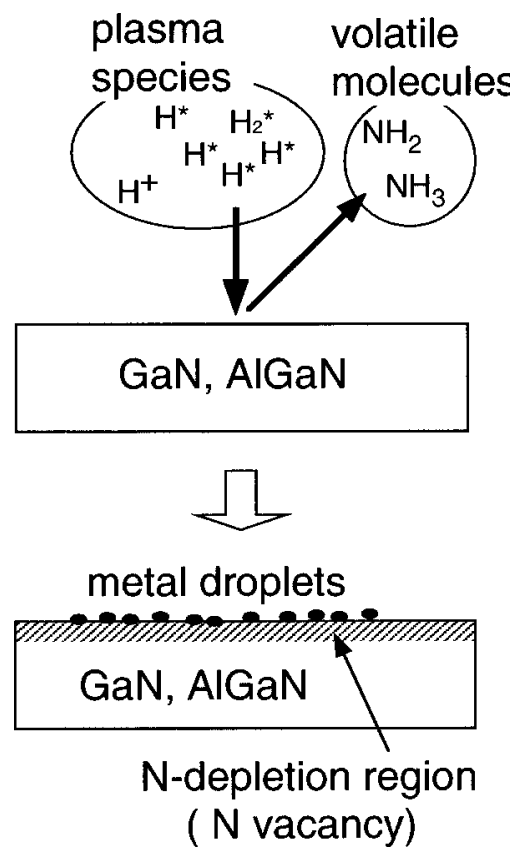

FIG. 8. Schematic illustration for a possible reaction process on $\mathrm{GaN}$ or AlGaN surfaces during the $\mathrm{H}_{2}$-plasma treatment.

ates resonant levels in the conduction band and contributes to the conduction band edge, supplying free electrons in GaN. On the other hand, recent results of calculation using the Green's function method by Yamaguchi and Junnarkar ${ }^{31}$ predicted that the $V_{\mathrm{N}}$ defect can form an s-like discrete deep level within the gap. Thus, these suggest a possibility that $\mathrm{N}$-vacancy-related clusters and/or defects may act as donortype deep levels.

On the other hand, no such decrease of $\mathrm{N}$ atoms was observed after the $\mathrm{N}_{2}$-plasma treatment, although it was also effective in removing oxides from the surface. As compared with the air-exposed AlGaN surface, the peak shift of 0.4$0.5 \mathrm{eV}$ toward higher binding energies was observed in the $\mathrm{Al} 2 p$ spectrum in the $\mathrm{N}_{2}$-plasma treated $\mathrm{AlGaN}$ surface, as shown in Fig. 7. A similar peak shift was also observed in XPS core levels at the $\mathrm{N}_{2}$-plasma treated $\mathrm{GaN}$ surface. These peak shifts indicate the reduction of the surface band bending. ${ }^{9}$ Thus, the ECR-N 2 plasma treatment seems to partially recover or terminate surface defects, leading to the reduction of densities of surface states on $\mathrm{GaN}$ and $\mathrm{AlGaN}$.

\section{B. Surface passivation of $\mathrm{GaN}$ and GaN/AIGaN surfaces by $\mathrm{SiO}_{2}$ and $\mathrm{SiN}_{x}$}

Electrical properties of the passivated GaN surfaces were investigated using MIS structures. Figure 9 shows typical $C-V$ curves obtained from the $\mathrm{SiO}_{2} / n-\mathrm{GaN}$ and the $\mathrm{SiN}_{x} / n$-GaN MIS structures where the dielectric films were deposited on the GaN surfaces after the ECR- $\mathrm{N}_{2}$ plasma treatment. Also shown are the calculated curves based on the accumulation, depletion and inversion behavior for the MIS structure. ${ }^{32}$ For calculation, an effective electron mass of 


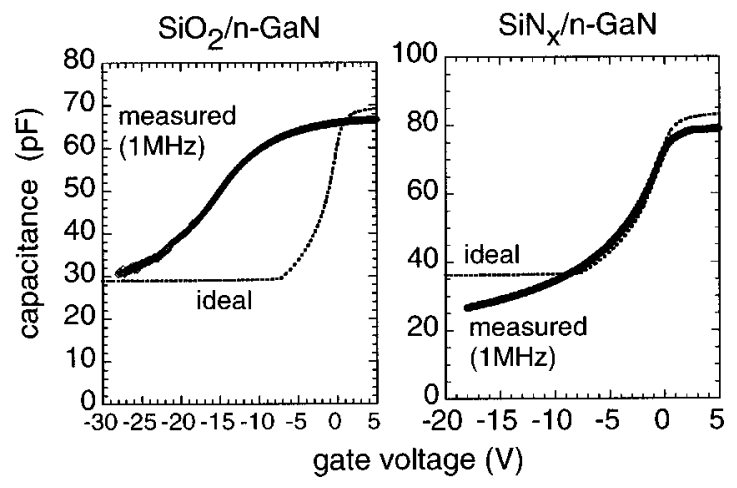

FIG. 9. Typical $C-V$ curves obtained from the $\mathrm{SiO}_{2} / n-\mathrm{GaN}$ and $\mathrm{SiN}_{x} / n$-GaN MIS structures prepared by ECR CVD. The GaN surfaces were treated in the $\mathrm{N}_{2}$ plasma before the deposition of dielectric films.

$0.2 m_{0}$, an effective hole mass of $0.8 m_{0}$, a dielectric constant of 9.5 and an energy gap of $3.40 \mathrm{eV}$ were used for $\mathrm{GaN}$ at room temperature.

Poor $C-V$ behavior was observed in the $\mathrm{SiO}_{2}$-passivated sample, in spite of the fact that a natural oxide layer was almost removed from the $\mathrm{GaN}$ surfaces by the $\mathrm{N}_{2}$-plasma treatment. A large discrepancy between the measured and calculated curves, including gradual slope in capacitance change from the accumulation region to the depletion region, indicates the existence of high-density interface states. In contrast, the $\mathrm{SiN}_{x} / \mathrm{GaN}$ structure showed better $C-V$ characteristics. The measured $C-V$ curve was very close to the calculated one, and clear deep depletion behavior was observed even at room temperature. Similar deep depletion features with no inversion characteristics were reported in $\mathrm{SiO}_{2} / \mathrm{GaN}$ (Ref. 22) and $\mathrm{SiO}_{2} / \mathrm{SiC}$ systems, ${ }^{33}$ because the generation rate of the minority carriers (holes in this case) is extremely low at room temperature in wide-gap semiconductor MIS systems. These results indicated that the $\mathrm{SiN}_{x}$-gate control of surface potential was achieved over a remarkably wide within the bandgap of $\mathrm{GaN}$.

Figure 10 shows distributions of interface state density $\left(D_{\text {it }}\right)$ of the $\mathrm{SiO}_{2} / n-\mathrm{GaN}$ and $\mathrm{SiN}_{x} / n-\mathrm{GaN}$ structures, which

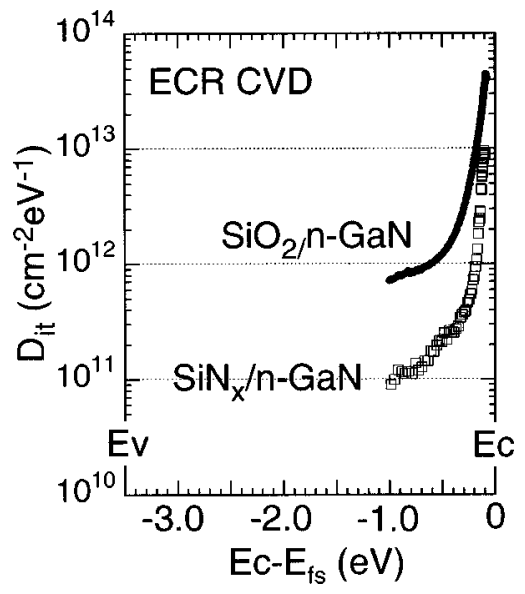

FIG. 10. Distributions of interface state density $\left(D_{\mathrm{it}}\right)$ of the $\mathrm{SiO}_{2} / n-\mathrm{GaN}$ and $\mathrm{SiN}_{x} / n-\mathrm{GaN}$ structures.

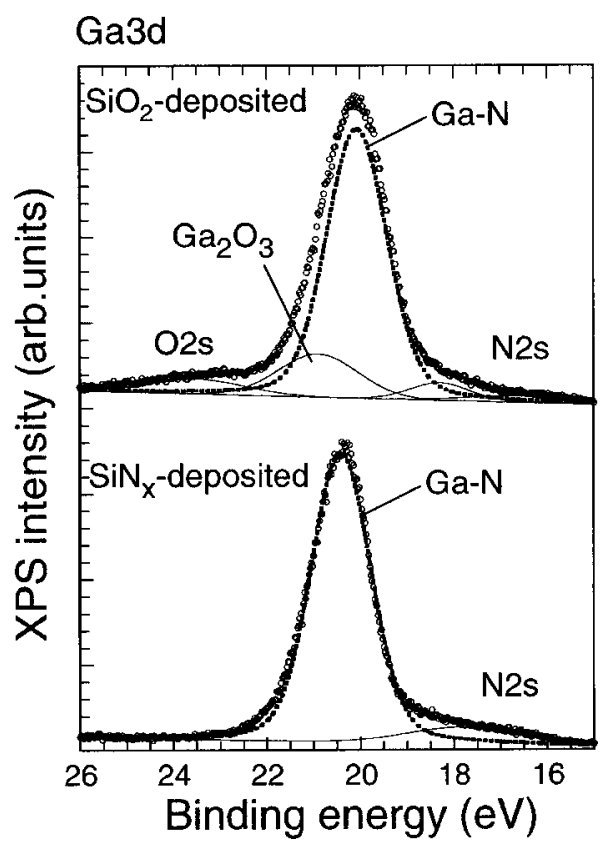

FIG. 11. In situ XPS Ga $3 d$ spectra obtained from $\mathrm{SiO}_{2}$ - and $\mathrm{SiN}_{x}$-deposited $\mathrm{GaN}$ surfaces. The thickness of insulating film is $2 \mathrm{~nm}$.

were calculated by applying the Terman method to the measured $C-V$ curves at room temperature. ${ }^{32}$ One of the essential conditions for the Terman method is that the change in interface charges corresponding to the state density can appear in the shift in the measured $C-V$ curve. For wide-gap semiconductors, however, there are some cases where this condition does not apply. It is expected, for example, that the states near midgap have large time constants for carrier emission. In this case, the charging state is remained almost unchanged during the gate voltage sweep even if the interface states have high densities. Thus, we estimated the limitation of applying the Terman method to calculation of interface state density in terms of the carrier emission time from the interface state at RT. The results showed that one cannot evaluate densities of interface states at the energies below $E_{C^{-}}-1.0 \mathrm{eV}$ from $C-V$ measurements at RT, due to the extremely long carrier emission times from the corresponding states.

As shown in Fig. 10, the presence of high-density interface states seriously disturb a smooth gate control of the surface potential for the $\mathrm{SiO}_{2} / n-\mathrm{GaN}$ structure. We detected an interfacial Ga-oxide peak in XPS Ga $3 d$ spectrum in the separate $\mathrm{SiO}_{2} / \mathrm{GaN}$ sample having a very thin $(2 \mathrm{~nm}) \mathrm{SiO}_{2}$ layer, as shown in Fig. 11(a). In the initial stage of the $\mathrm{SiO}_{2}$ deposition, unexpected and uncontrollable oxidation reaction could take place at the GaN surface due to the supply of oxygen-related active ions and/or radicals. Formation of such an interfacial oxide is believed to be one of the reasons for the degradation of electrical properties of the $\mathrm{SiO}_{2} / \mathrm{GaN}$ interface.

In comparison with the $\mathrm{SiO}_{2} / n-\mathrm{GaN}$ interface, the $\mathrm{SiN}_{x} / \mathrm{GaN}$ structures showed relatively low densities of interface states, as shown in Fig. 10. Since the control 


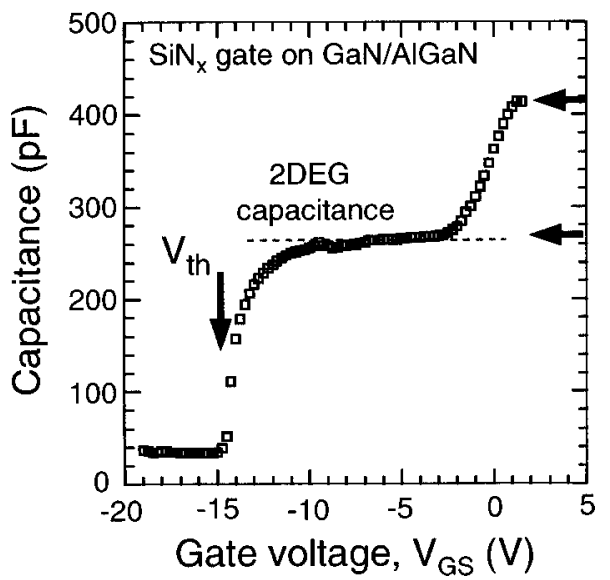

FIG. 12. $C-V$ characteristics of the $\mathrm{SiN}_{x}$-gate structure formed on the $\mathrm{GaN} /$ AlGaN surface.

$\mathrm{SiN}_{x} / \mathrm{GaN}$ sample without the $\mathrm{N}_{2}$-plasma treatment showed higher $D_{\text {it }}$ values ranging from $3 \times 10^{11}$ to 5 $\times 10^{11} \mathrm{~cm}^{-2} \mathrm{eV}^{-1}$, the $\mathrm{N}_{2}$-plasma treatment is effective in improving interface properties. No interfacial oxide was detected at the $\operatorname{SiN}_{x} / \mathrm{GaN}$ interface, as shown in Fig. 11(b). Furthermore, the Raman spectra taken by the backscattering geometry at RT indicated no pronounced stress at the GaN surface covered with a $\operatorname{SiN}_{x}$ film.

The present $\mathrm{SiN}_{x}$-based passivation was applied to the surface of GaN/AlGaN heterostructure. Figure 12 shows the $C-V$ characteristics of the $\mathrm{SiN}_{x}$-gate structure formed on the GaN/AlGaN surface. The thickness of the $\operatorname{SiN}_{x}$ film is $41 \mathrm{~nm}$ and the electrode diameter is $600 \mu \mathrm{m}$. The measured $C-V$ curve clearly indicates a plateau region, reflecting the presence of 2DEG at the GaN/AlGaN interface. Thus, the capacitance value at the plateau region can easily be estimated from the total capacitance given by the AlGaN barrier capacitance and the $\mathrm{SiN}_{x}$ insulator capacitance. The estimated value was well in agreement with the experimental one. The maximum capacitance at round $V_{\mathrm{GS}}=2 \mathrm{~V}$ also corresponded to the $\mathrm{SiN}_{x}$ insulator capacitance. In addition, the experimental threshold voltage, $V_{\text {th }}$, is reasonably close to a simple estimation using $V_{\mathrm{th}}=\Phi_{\mathrm{B}}-q \mathrm{n}_{s} / C_{T}$ (here, $\Phi_{B}$ is the potential barrier at the $\operatorname{SiN}_{x}$ surface, $n_{s}$ is the 2DEG density and the $C_{T}$ is the total capacitance in unit area). These results indicate that the $\mathrm{SiN}_{x}$-insulated gate can control the potential in the AlGaN barrier layer, thereby leading to the expected modulation of the 2DEG density.

All these results indicated that the $\mathrm{SiN}_{x}$-based passivation structure achieved good electronic properties of the $\mathrm{GaN}$ and $\mathrm{AlGaN}$ insulator-semiconductor interfaces. However, a negative issue appeared in the leakage characteristics. Figure 13(a) showed $I-V$ characteristics of the $\mathrm{Al} / \mathrm{SiN}_{x} / n-\mathrm{Al}_{0.3} \mathrm{Ga}_{0.7} \mathrm{~N}$ structure with the $\mathrm{SiN}_{x}$ thickness of $20 \mathrm{~nm}$. For comparison, the $I-V$ curves of $\mathrm{Ni} / n-\mathrm{Al}_{0.3} \mathrm{Ga}_{0.7} \mathrm{~N}$ and $\mathrm{Al} / \mathrm{SiN}_{x} / n-\mathrm{Si}$ structures were plotted in Fig. 13(a). As expected, the $\mathrm{SiN}_{x}$-insulated gate drastically reduced leakage currents in the reverse bias condition, as compared with the Schottky gate structure. For forward bias, however, a steep

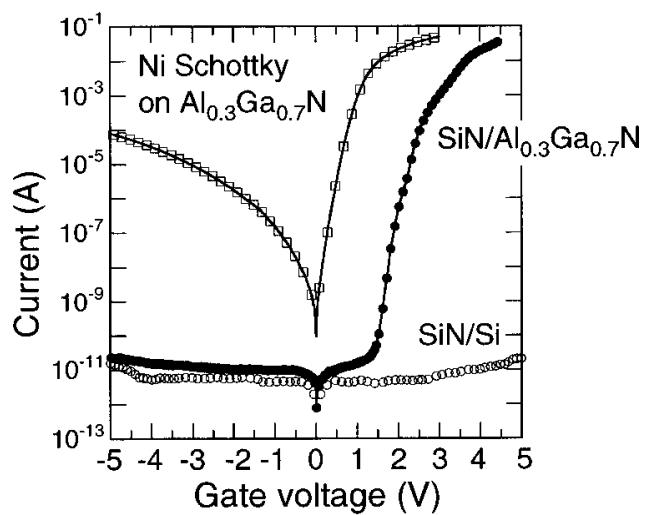

(a)

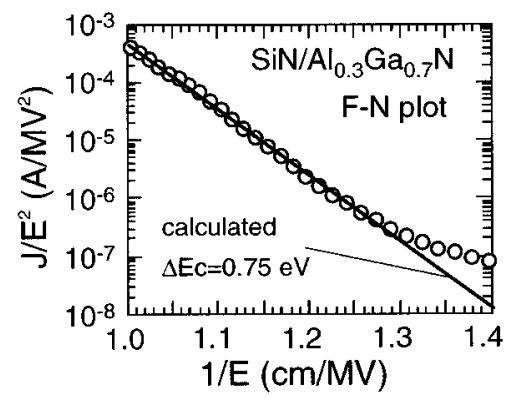

(b)

FIG. 13. (a) $I-V$ characteristics of the $\mathrm{Al} / \mathrm{SiN}_{x} / n-\mathrm{Al}_{0.3} \mathrm{Ga}_{0.7} \mathrm{~N}$ structure with the $\mathrm{SiN}_{x}$ thickness of $20 \mathrm{~nm}$. For comparison, the $I-V$ curves of $\mathrm{Ni} / n-\mathrm{Al}_{0.3} \mathrm{Ga}_{0.7} \mathrm{~N}$ and $\mathrm{Al} / \mathrm{SiN}_{x} / n$-Si structures are plotted. (b) The plots of $\log \left(J / E^{2}\right)$ vs $1 / E$ for the $\mathrm{SiN}_{x} / n-\mathrm{Al}_{0.3} \mathrm{Ga}_{0.7} \mathrm{~N}$ structure.

increase of leakage current was observed at around $V_{G}$ $=1.5 \mathrm{~V}$ for the $\mathrm{SiN}_{x} / n-\mathrm{Al}_{0.3} \mathrm{Ga}_{0.7} \mathrm{~N}$ system, while the $\mathrm{SiN}_{x} / n$-Si structure keeps the low level of leakage current. We have replotted the $I-V$ data at a large leakage region for the $\mathrm{Al} / \mathrm{SiN}_{x} / n$ - $\mathrm{AlGaN}$ structure in the form of $\log \left(J / E^{2}\right)$ vs $1 / E$ (here, $J$ is the current density and $E$ is electric field). The result is shown in Fig. 13(b). The linear relation of $\log \left(J / E^{2}\right)$ vs $1 / E$ indicates that the leakage is governed by the FowlerNordheim (FN) tunneling mechanism. From the fitting to this linear relation, we obtained the tunneling barrier height of $0.75 \mathrm{eV}$, corresponding to the conduction band offset, $\Delta E_{C}$, between $\mathrm{SiN}_{x}$ and $\mathrm{Al}_{0.3} \mathrm{Ga}_{0.7} \mathrm{~N}$. In the fitting, we assumed the effective mass of electron in $\operatorname{SiN}_{x}$ to be $m_{e}^{*}=0.30 m_{0}\left(m_{0}\right.$ : electron rest mass), often used in the $\mathrm{SiO}_{2} / \mathrm{Si}$ system.

In order to investigate a band alignment between $\mathrm{SiN}_{x}$ and $\mathrm{Al}_{0.3} \mathrm{Ga}_{0.7} \mathrm{~N}$, the XPS analysis was employed in the $\mathrm{SiN}_{x} / \mathrm{Al}_{0.3} \mathrm{Ga}_{0.7} \mathrm{~N}$ structures. Figure $14(\mathrm{a})$ shows the $\mathrm{N} 1 \mathrm{~s}$ spectrum obtained from a thick $\operatorname{SiN}_{x}$ film $(20 \mathrm{~nm})$ on $\mathrm{Al}_{0.3} \mathrm{Ga}_{0.7} \mathrm{~N}$. From the onset of the energy loss peak, we estimated the bandgap of $\mathrm{SiN}_{x}$ to be $4.9 \mathrm{eV}$. Miyazaki ${ }^{34}$ reported the value of $4.75 \mathrm{eV}$ for the $\mathrm{SiN}_{x} / \mathrm{Si}$ structure. Then, we estimated the valence band offset, $\Delta E_{V}$, between $\operatorname{SiN}_{x}$ and $\mathrm{Al}_{0.3} \mathrm{Ga}_{0.7} \mathrm{~N}$ also from the XPS analysis. ${ }^{35,36}$ This was carried out by measuring the energy difference between the Si $2 p$ and $\mathrm{Al} 2 p$ core levels in the $\mathrm{SiN}_{x} / \mathrm{Al}_{0.3} \mathrm{Ga}_{0.7} \mathrm{~N}$ structures having a thin $\operatorname{SiN}_{x}$ film $(2 \mathrm{~nm})$. The band alignment obtained is schematically shown in Fig. 14(b). A relatively small value of $\Delta E_{C}=0.7 \mathrm{eV}$ was obtained, and this is well in 


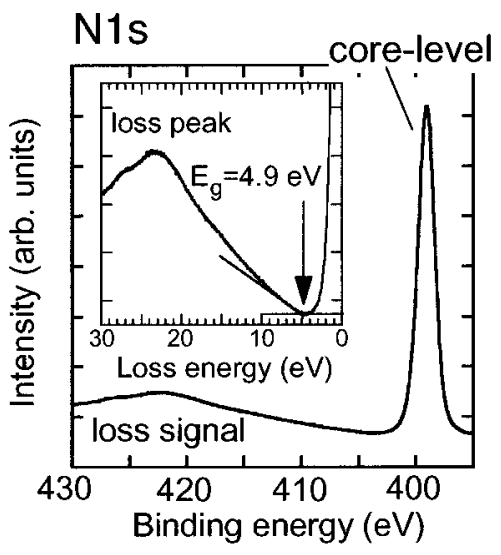

(a)

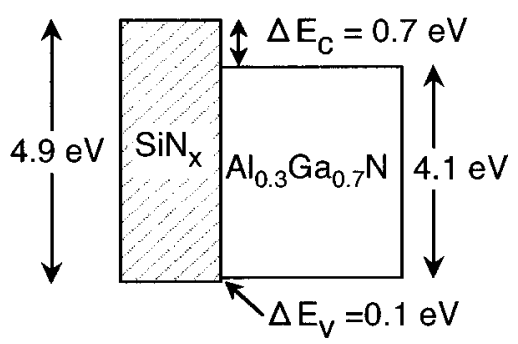

(b)

FIG. 14. (a) XPS N $1 s$ spectrum obtained from a thick $\operatorname{SiN}_{x}$ film $(20 \mathrm{~nm})$ on $\mathrm{Al}_{0.3} \mathrm{Ga}_{0.7} \mathrm{~N}$ and (b) band alignment between $\mathrm{SiN}_{x}$ and $\mathrm{Al}_{0.3} \mathrm{Ga}_{0.7} \mathrm{~N}$.

agreement with that estimated by the F-N fitting method [Fig. 13(b)]. Thus, a serious leakage problem can arise from the band alignment at the $\mathrm{SiN}_{x} / \mathrm{Al}_{0.3} \mathrm{Ga}_{0.7} \mathrm{~N}$ interface, thereby limiting the application of the $\mathrm{SiN}_{x}$-based passivation structure to an insulated gate structure on GaN/AlGaN HFET system.

\section{Novel $\mathrm{Al}_{2} \mathrm{O}_{3}$-based passivation structure}

As described in the Introduction, an $\mathrm{Al}_{2} \mathrm{O}_{3}$ film has a large band gap, a large dielectric constant and a high breakdown field. This indicates an advantage of $\mathrm{Al}_{2} \mathrm{O}_{3}$ as an insulated gate for the GaN/AlGaN HFETs. In order to form a thin $\mathrm{Al}_{2} \mathrm{O}_{3}$ film on $\mathrm{AlGaN}$ and to control the $\mathrm{Al}_{2} \mathrm{O}_{3} / \mathrm{AlGaN}$ interface properties, we have employed the molecular beam deposition of $\mathrm{Al}$ and the subsequent $\mathrm{ECR}-\mathrm{O}_{2}$ plasma oxidation in in situ fashion.

The $\mathrm{Al}_{2} \mathrm{O}_{3}$ layer was fabricated through the following steps: The GaN/AlGaN surface was treated in $\mathrm{NH}_{4} \mathrm{OH}$ solution at $50{ }^{\circ} \mathrm{C}$ for $10 \mathrm{~min}$ in air followed by the ECR-N $\mathrm{N}_{2}$ plasma treatment of the surface at $280^{\circ} \mathrm{C}$ for $1 \mathrm{~min}$. Then, an Al layer with a nominal thickness of $3 \mathrm{~nm}$ was deposited on the AlGaN surface at a deposition rate of $0.01 \mathrm{~nm} / \mathrm{s}$ at $\mathrm{RT}$ in the MBE chamber (base pressure: $2 \times 10^{-10}$ Torr). The top Al layer was then oxidized using ECR-excited $\mathrm{O}_{2}$ plasma at RT for $5 \mathrm{~min}$ in the ECR CVD chamber. Finally, the sample was annealed at $700{ }^{\circ} \mathrm{C}$ for $10 \mathrm{~min}$ in the UHV annealing chamber. The AFM observation showed that the surface morphology maintained the smoothness with the characteristic feature dominated by monolayer steps, even after the passi-

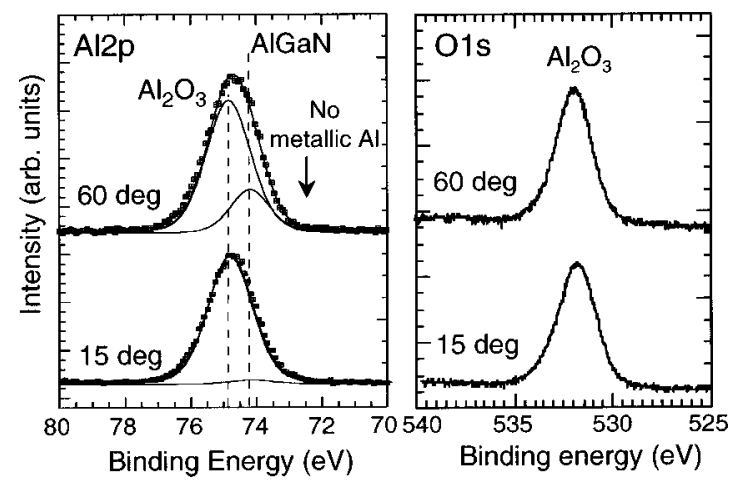

FIG. 15. XPS Al $2 p$ and $\mathrm{O} 1 s$ spectra obtained from the GaN/AlGaN surface after the formation of a thin $\mathrm{Al}_{2} \mathrm{O}_{3}$ film.

vation process. A comparable rms roughness value of 0.33 $\mathrm{nm}$ to the as-grown sample was obtained from the passivated AlGaN surface.

Figure 15 shows the XPS $\mathrm{Al} 2 p$ and $\mathrm{O} 1 s$ spectra obtained from the GaN/AlGaN surface after the formation of the thin $\mathrm{Al}$ oxide layer. In the $\mathrm{Al} 2 p$ spectra, no metallic $\mathrm{Al}$ peak was detected. The peak could be deconvoluted into two components corresponding to the $\mathrm{Al}-\mathrm{O}$ bond and the $\mathrm{Al}-\mathrm{N}$ bond. The Al-N peak intensity increased with an escape angle of photoelectrons. On the other hand, the Al-O peak intensity almost remained unchanged, similar to the behavior of the $\mathrm{O} 1 s$ peak. Furthermore, we confirmed no change in the spectra of Ga- and $\mathrm{N}$-core levels before and after the formation process. These results indicated that a thin $\mathrm{Al}$ oxide layer was successfully formed on the top of GaN/AlGaN surface without disordering the chemical properties of the underneath AlGaN surface. From the comparison of integrated intensity ratios of $\mathrm{O} 1 s$ to $\mathrm{Al} 2 p$ between the formed $\mathrm{Al}$ oxide and a crystalline sapphire substrate as a standard, the composition of the present $\mathrm{Al}$ oxide was found to be $\mathrm{Al}_{2} \mathrm{O}_{3}$. The thickness of the $\mathrm{Al}_{2} \mathrm{O}_{3}$ layer was estimated to be $3.5 \mathrm{~nm}$ from the angle-resolved analysis of the $\mathrm{Al} 2 p$ corelevel intensities.

Figures 16(a) and 16(b) show the XPS O $1 s$ spectrum of the $\mathrm{Al}_{2} \mathrm{O}_{3}$-passivated $\mathrm{GaN} / \mathrm{Al}_{0.3} \mathrm{Ga}_{0.7} \mathrm{~N}$ surface and the valence-band spectra of the surface before and after the passivation. The band gap, $E_{G}$, of the thin $\mathrm{Al}_{2} \mathrm{O}_{3}$ layer can be determined from the onset position of the energy loss peak in the $\mathrm{O} 1 s$ spectrum. As shown in Fig. 16(a), this analysis gave $E_{G}=7.0 \mathrm{eV}$. The valence band spectrum before the passivation showed a characteristic feature of "free" AlGaN surface consisting of Ga $4 s, \mathrm{Al} 3 p$, and N $2 p$ orbits. ${ }^{35}$ After the surface passivation, a drastic change in the spectrum appeared, reflecting the formation of the $\mathrm{Al}_{2} \mathrm{O}_{3}$ layer. The valence band offset, $\Delta E_{V}$, was estimated to be $0.8 \mathrm{eV}$ from the energy difference between the leading edges of the valence-band spectra before and after the passivation, as shown in Fig. 16(b). From the values $E_{G}=4.1 \mathrm{eV}$ for $\mathrm{Al}_{0.3} \mathrm{Ga}_{0.7} \mathrm{~N}, E_{G}$ $=7.0 \mathrm{eV}$ for $\mathrm{Al}_{2} \mathrm{O}_{3}$, and $\Delta E_{V}=0.8 \mathrm{eV}$, the conduction band offset, $\Delta E_{C}$, was estimated to be $2.1 \mathrm{eV}$. The obtained band alignment between $\mathrm{Al}_{2} \mathrm{O}_{3}$ and $\mathrm{Al}_{0.3} \mathrm{Ga}_{0.7} \mathrm{~N}$ is shown in Fig. 16(c). 


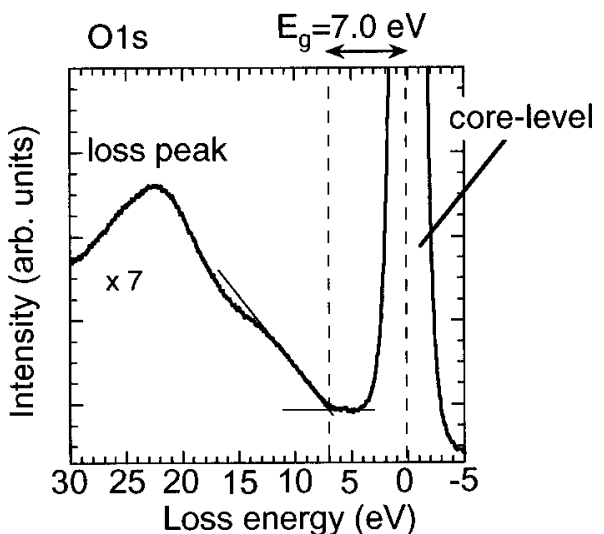

(a)

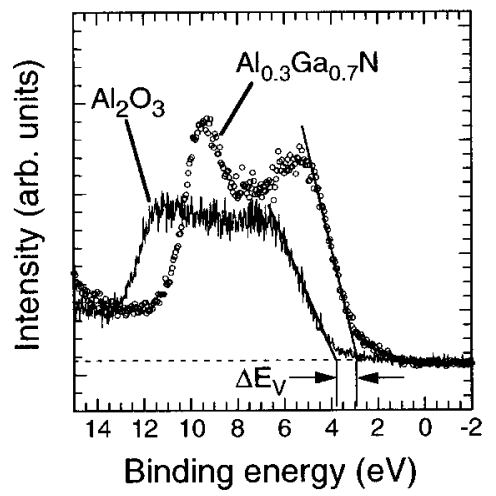

(b)

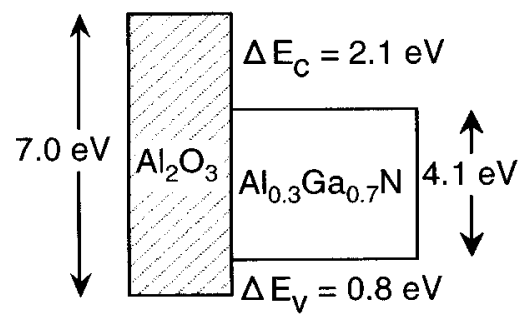

(c)

FIG. 16. (a) XPS $\mathrm{O} 1 \mathrm{~s}$ spectrum of the $\mathrm{Al}_{2} \mathrm{O}_{3}$-passivated $\mathrm{Al}_{0.3} \mathrm{Ga}_{0.7} \mathrm{~N}$ surface, (b) the valence-band spectra of the $\mathrm{Al}_{0.3} \mathrm{Ga}_{0.7} \mathrm{~N}$ surface before and after the passivation, and (c) band alignment between $\mathrm{Al}_{2} \mathrm{O}_{3}$ and $\mathrm{Al}_{0.3} \mathrm{Ga}_{0.7} \mathrm{~N}$.

This band structure led to the reduction of leakage currents at forward bias as compared with the Ni-Schottky gate and the $\mathrm{SiN}_{x}$-insulated gate structures, as shown in Fig. 17, in spite of a very small thickness of the $\mathrm{Al}_{2} \mathrm{O}_{3}$ layer of 3.5 $\mathrm{nm}$. A slope of gradual increase in leakage current for the $\mathrm{Al}_{2} \mathrm{O}_{3}$-insulated gate at forward bias is less than that of the $\mathrm{SiN}_{x}$-insulated gate, indicating a direct tunneling mechanism in leakage through the $\mathrm{Al}_{2} \mathrm{O}_{3}$ layer rather than the FN tunneling.

\section{Application of the $\mathrm{Al}_{2} \mathrm{O}_{3}$-based passivation structure to insulated-gate GaN/AIGaN HFET}

The present $\mathrm{Al}_{2} \mathrm{O}_{3}$-based passivation structure was applied to the fabrication of an insulated-gate type GaN/AlGaN HFET. The device structure is schematically shown in Fig. 18. After the device isolation and Ohmic electrode metalli-

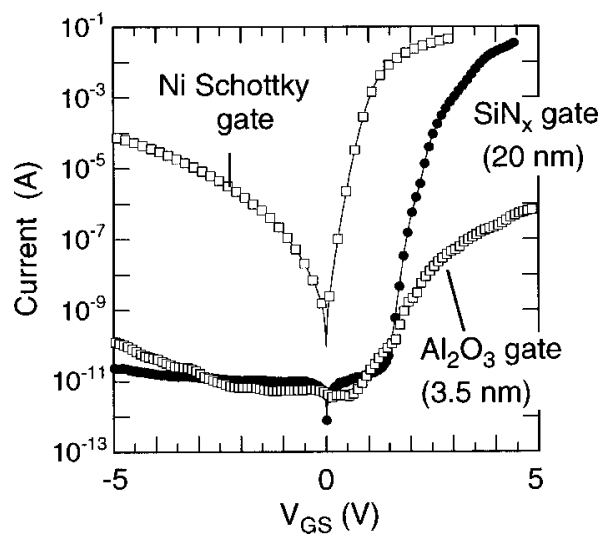

FIG. 17. $I-V$ characteristics of the Ni-Schottky gate, $\mathrm{SiN}_{x}$-insulated gate and $\mathrm{Al}_{2} \mathrm{O}_{3}$-insulated gate structures.

zation, the surface of GaN/AlGaN HFET structure was passivated by the thin $\mathrm{Al}_{2} \mathrm{O}_{3}$ layer through a process described in the previous section. Subsequently, the submicron metalgate patterns were defined and fabricated by a combination of electron-beam lithography and lift-off techniques.

Figure 19 shows typical drain $I-V$ characteristics of the fabricated $\mathrm{Al}_{2} \mathrm{O}_{3}$ insulated-gate (IG) HFET and Schottkygate (SG) HFET with a gate length of $0.4 \mu \mathrm{m}$. The $\mathrm{Al}_{2} \mathrm{O}_{3}$ IG HFET showed a good gate controllability up to $V_{\mathrm{GS}}=$ $+3 \mathrm{~V}$ and achieved high drain saturation current of about 0.8 $\mathrm{A} / \mathrm{mm}$, as shown in Fig. 19(a). These characteristics are better than SG HFET. The observed maximum $g_{m}$ value is 120 $\mathrm{mS} / \mathrm{mm}$.

We investigated current collapse characteristics under a quiescent gate voltage stress. ${ }^{19}$ The result is shown in Fig. 20 . During the measurement, the drain voltage, $V_{\mathrm{DS}}$, was kept at $15 \mathrm{~V}$. First, we set the initial gate voltage as $V_{\mathrm{GS} 0}$ $=0 \mathrm{~V}$ for $10 \mathrm{~s}$. After that, $V_{\mathrm{GS}}$ was switched to $+1 \mathrm{~V}$ instantaneously and then decreased to $-8 \mathrm{~V}$ with a sweeping rate of $0.2 \mathrm{~V} / \mathrm{s}$. This measurement mode is indicated by "normal mode" in Fig. 20. In the "stress mode," on the other hand, we applied $V_{\mathrm{GS}}=-8 \mathrm{~V}$ (far below the threshold voltage) for $10 \mathrm{~s}$ as the initial stress of the gate voltage. Then, the $V_{\mathrm{GS}}$ sweeping was carried out from $+1 \mathrm{~V}$ to $-8 \mathrm{~V}$. As shown in Fig. 20(a), a significant collapse was observed more than $10 \%$ in the drain currents for the SG HFET. On the other

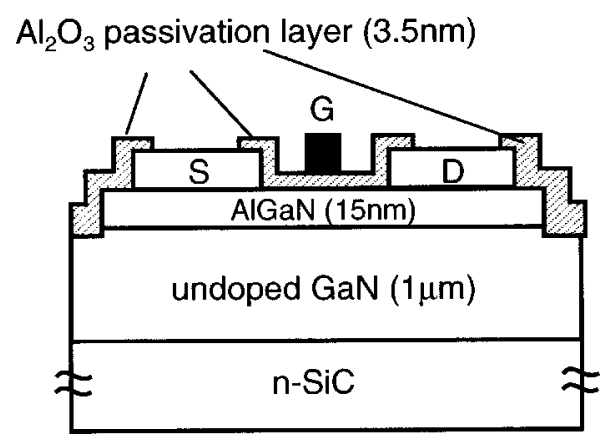

FIG. 18. Schematic illustration of insulated-gate type GaN/AlGaN HFETs with the $\mathrm{Al}_{2} \mathrm{O}_{3}$-based surface passivation structure. 

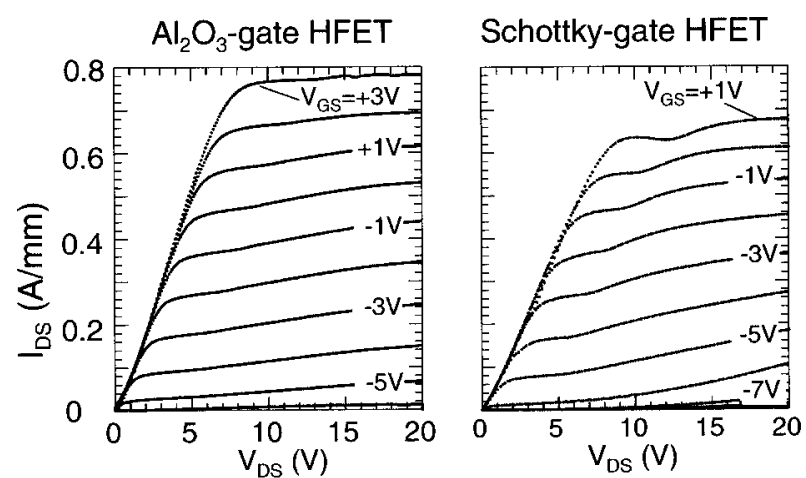

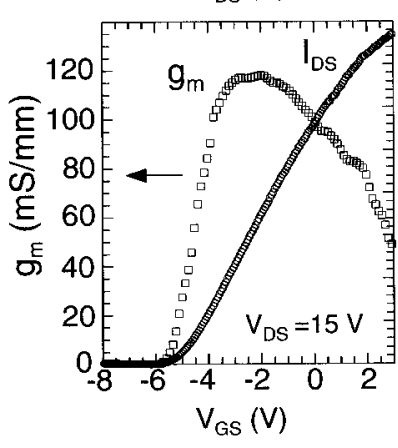

(a)

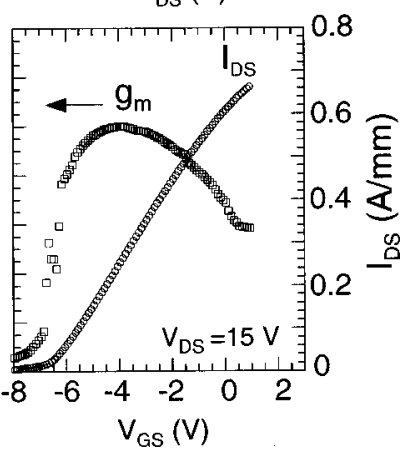

(b)
FIG. 19. $I-V$ characteristics of the fabricated (a) $\mathrm{Al}_{2} \mathrm{O}_{3}$ insulated-gate (IG) HFET and (b) Schottky-gate (SG) HFET with a gate length of $0.4 \mu \mathrm{m}$.

hand, no current collapse was observed for the IG HFET. This indicates a remarkable advantage of the present $\mathrm{Al}_{2} \mathrm{O}_{3}$-based passivation structure.

The current collapse effects have often been observed GaN/AlGaN SG HFETs under quiescent gate stress ${ }^{19}$ or pulse-mode gate stress. ${ }^{17,18,24,37}$ The collapse is also induced by drain stress. ${ }^{1,18,37}$ The mechanism for the current collapse is not clarified yet. Since a $\mathrm{SiN}_{x}$-based surface passivation dramatically reduces the current collapse, ${ }^{1,17-19}$ some models based on the electron trapping by surface states have been proposed. ${ }^{1,19}$ As described in the Sec. III A, the $\mathrm{H}_{2}$-plasma treatment produces $N$-vacancy related defects on $\mathrm{GaN}$ and

(a) Schottky-gate HFET

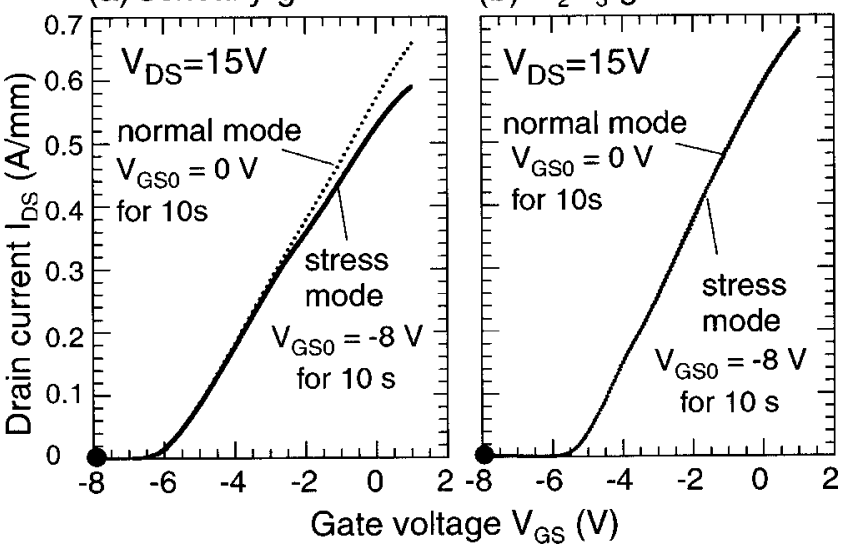

FIG. 20. $I_{\mathrm{DS}}-V_{\mathrm{GS}}$ characteristics of (a) the Schottky-gate HFET and (b) the $\mathrm{Al}_{2} \mathrm{O}_{3}$ insulated-gate HFET before and after the gate stress. $V_{\mathrm{GS} 0}$ indicates the initial gate voltage stress.
AlGaN surfaces. We have also found that the ECR-N 2 plasma treatment is very effective in suppressing the formation of such $N$-vacancy-related surface defects. ${ }^{9,27}$ Based on these findings, Hasegawa and co-workers ${ }^{27,38,39}$ have recently proposed a unified surface model that the electronic states consisting of $\mathrm{N}$-vacancy related surface levels and U-shaped surface state continuum are responsible for the electron trapping on GaN/AlGaN heterostructure surfaces. In case of SG HFETs, electrons can be injected into the surface states assisted by large leakage currents under the deep gate stress. The present $\mathrm{Al}_{2} \mathrm{O}_{3}$-based passivation process including ECR-N $\mathrm{N}_{2}$ plasma treatment can suppress the formation of $N$-vacancy related near-surface levels as well as surface states. In addition, the $\mathrm{Al}_{2} \mathrm{O}_{3}$ IG structure remarkably reduces the gate leakage currents. Thus, our $\mathrm{Al}_{2} \mathrm{O}_{3}$-based insulated gate and surface passivation structure is very effective in suppressing the current collapse effects, thereby leading to the reliability improvement of $\mathrm{AlGaN} / \mathrm{GaN}$ HFETs.

\section{CONCLUSION}

We have investigated the effects of plasma processing, formation of Si-based dielectrics and formation of a thin $\mathrm{Al}_{2} \mathrm{O}_{3}$ film on the chemical and electronic properties of $\mathrm{GaN}$ and $\mathrm{AlGaN}$ surfaces. The ECR- $\mathrm{H}_{2}$-plasma treatment was found to produce nitrogen-vacancy-related defect levels at $\mathrm{GaN}$ and AlGaN surfaces, while the treatment in ECR-N plasma improved the electronic properties of surfaces. The deposition of $\mathrm{SiO}_{2}$ film on $\mathrm{GaN}$ and $\mathrm{AlGaN}$ surfaces induced high-density interface states, due to unexpected and uncontrollable oxidation reactions on the surfaces during the deposition process. In comparison, the $\mathrm{SiN}_{x} / \mathrm{GaN}$ passivation structure prepared by ECR CVD with the $\mathrm{N}_{2}$-plasma pretreatment showed good interface properties with the minimum $D_{\text {it }}$ value of $1 \times 10^{11} \mathrm{~cm}^{-2} \mathrm{eV}^{-1}$. No pronounced stress remained at the $\mathrm{SiN}_{x} / \mathrm{GaN}$ interface. Excess leakage currents based on the Fowler-Nordheim tunneling were observed in the $\mathrm{SiN}_{x} / \mathrm{Al}_{0.3} \mathrm{Ga}_{0.7} \mathrm{~N}$ structure, due to a relatively small conduction band offset, $\Delta E_{C}$, of $0.7 \mathrm{eV}$ between $\mathrm{SiN}_{x}$ and $\mathrm{Al}_{0.3} \mathrm{Ga}_{0.7} \mathrm{~N}$. A novel $\mathrm{Al}_{2} \mathrm{O}_{3}$-based passivation structure was successfully formed on the AlGaN surface by molecular beam deposition of $\mathrm{Al}$ and the subsequent ECR-O - -plasma oxidation. In situ XPS analysis showed a band gap of $7.0 \mathrm{eV}$ for the formed $\mathrm{Al}_{2} \mathrm{O}_{3}$ layer with a thickness of $3.5 \mathrm{~nm}$ and a sufficiently large $\Delta E_{C}$ of $2.1 \mathrm{eV}$ between $\mathrm{Al}_{2} \mathrm{O}_{3}$ and $\mathrm{Al}_{0.3} \mathrm{Ga}_{0.7} \mathrm{~N}$. The GaN/AlGaN insulated-gate HFETs having the $\mathrm{Al}_{2} \mathrm{O}_{3}$-based passivation structure showed a good gate control of drain currents up to $V_{\mathrm{GS}}=+3 \mathrm{~V}$ and achieved drain saturation current of $0.8 \mathrm{~A} / \mathrm{mm}$. The observed maximum $g_{m}$ value is $120 \mathrm{mS} / \mathrm{mm}$. No current collapse was observed in the $\mathrm{Al}_{2} \mathrm{O}_{3}$ IG HFETs. These results indicate a remarkable advantage of the present $\mathrm{Al}_{2} \mathrm{O}_{3}$-based passivation structure for GaN/AlGaN HFETs, leading to the reliability improvement of AlGaN/GaN HFETs. 


\section{ACKNOWLEDGMENTS}

This work was partly supported by the $21 \mathrm{C} \mathrm{COE} \mathrm{Project}$ on "Meme-Media Based Next Generation ITs" and grant-inaid for Scientific Research (B) (No. 14350155) from the Ministry of Science, Education, Sports, and Culture, Japan.

${ }^{1}$ R. Vetury, N. Q. Zhang, S. Keller, and U. K. Mishra, IEEE Trans. Electron Devices 48, 560 (2001).

${ }^{2}$ M. A. Kahn, X. Hu, A. Tarakji, G. Simin, J. Yang, R. Gaska, and M. S. Shur, Appl. Phys. Lett. 77, 1339 (2000).

${ }^{3}$ E. J. Miller, X. Z. Dang, and E. T. Yu, J. Appl. Phys. 88, 5951 (2000).

${ }^{4}$ E. D. Readinger, B. P. Luther, S. E. Mohney, and E. L. Piner, J. Appl. Phys. 89, 7983 (2001).

${ }^{5}$ S. W. King, J. P. Bamak, M. D. Bremser, K. M. Tracy, C. Ronning, and R. F. Davis, J. Appl. Phys. 84, 5248 (1998).

${ }^{6}$ P. J. Hartlieb, A. Roskowski, R. F. Davis, A. Platow, and R. J. Nemanich, J. Appl. Phys. 91, 732 (2002).

${ }^{7}$ T. Hashizume, S. Ootomo, R. Nakasaki, S. Oyama, and M. Kihara, Appl. Phys. Lett. 76, 2880 (2000).

${ }^{8}$ T. Hashizume, R. Nakasaki, S. Ootomo, S. Oyama, and H. Hasegawa, Mater. Sci. Eng., B 80, 309 (2001).

${ }^{9}$ T. Hashizume, S. Ootomo, S. Oyama, M. Konishi, and H. Hasegawa, J. Vac. Sci. Technol. B 19, 1675 (2001)

${ }^{10}$ S. C. Binari, L. B. Rowland, G. Kelner, W. Kruppa, H. B. Dietrich, K. Doverspike, and D. K. Gaskill, Proceedings of the 21st International Symposium on Compound Semiconductors, San Diego (1994).

${ }^{11}$ H. Kawai, M. Hara, F. Nakamura, and S. Imanaga, Electron. Lett. 34, 592 (1998).

${ }^{12}$ S. Imanaga, F. Nakamura, and H. Kawai, Jpn. J. Appl. Phys., Part 1 40, 1194 (2001).

${ }^{13}$ T. Hashizume, R. Nakasaki, and H. Hasegawa, Abstracts of 41st Electronic Materials Conference (1999), p. 29.

${ }^{14}$ R. Nakasaki, T. Hashizume, and H. Hasegawa, Physica E (Amsterdam) 7, 953 (2000).

${ }^{15}$ B. M. Green, K. K. Chu, E. M. Chumbes, J. A. Smart, J. M. Shealy, and L. F. Eastman, IEEE Electron Device Lett. 21, 268 (2000).

${ }^{16}$ J.-S. Lee, A. Vescan, A. Wieszt, R. Dietrich, H. Leier, and Y.-S. Kwon, Tech. Dig. - Int. Electron Devices Meet. 381 (2000).

${ }^{17}$ X. Hu, A. Koudymov, G. Simin, J. Yang, M. A. Khan, A. Tarakji, M. S. Shur, and R. Gaska, Appl. Phys. Lett. 79, 2832 (2001).
${ }^{18}$ T. Kikkawa, M. Nagahara, N. Okamoto, Y. Tateno, Y. Yamaguchi, N. Hara, K. Joshin, and P. M. Asbeck, Tech. Dig. - Int. Electron Devices Meet. 585 (2001).

${ }^{19}$ T. Mizutani, Y. Ohno, M. Akita, S. Kishimoto, and K. Maezawa, Phys. Status Solidi A 194, 447 (2002).

${ }^{20}$ R. Therrien, G. Lucovsky, and R. Davis, Appl. Surf. Sci. 166, 513 (2000).

${ }^{21}$ M. Hong, K. A. Anselm, J. Kwo, H. M. Ng, J. N. Baillargeon, A. R. Kortan, C. M. Lee, J. I. Chyi, and T. S. Lay, J. Vac. Sci. Technol. B 18, 1453 (2000).

${ }^{22}$ B. Gaffey, L. J. Guido, X. W. Wang, and T. P. Ma, IEEE Trans. Electron Devices 48, 458 (2001)

${ }^{23}$ K. Inoue, Y. Ikeda, H. Masato, T. Matsuno, and K. Nishi, Tech. Dig. - Int. Electron Devices Meet. 577 (2001).

${ }^{24}$ B. Luo, J. W. Johnson, J. Kim, R. M. Mahandru, F. Ren, B. P. Gila, A. H. Onstine, C. R. Abernathy, S. J. Pearton, A. G. Baca, R. D. Briggs, R. J. Shul, C. Monier, and J. Han, Appl. Phys. Lett. 80, 1661 (2002).

${ }^{25}$ Z. Jin, T. Hashizume, and H. Hasegawa, Appl. Surf. Sci. 190, 361 (2002).

${ }^{26}$ B. Heying, E. J. Tersa, C. R. Elsas, P. Fini, S. P. DenBaars, and J. S. Speck, J. Appl. Phys. 85, 6470 (1999).

${ }^{27}$ T. Inagaki, T. Hashizume, and H. Hasegawa, Appl. Surf. Sci. (in press).

${ }^{28}$ X. Y. Zhu, M. Wolf, and J. M. White, J. Vac. Sci. Technol. A 11, 838 (1993).

${ }^{29}$ J. Neugebauer and C. G. Van de Walle, Phys. Rev. B 50, 8067 (1994).

${ }^{30}$ P. Boguslawski, E. L. Briggs, and J. Bernholc, Phys. Rev. B 51, 17255 (1995).

${ }^{31}$ E. Yamaguchi and M. R. Junnarkar, J. Cryst. Growth 189/190, 570 (1998).

${ }^{32}$ E. H. Nicollian and J. R. Brews, MOS Physics and Technology (Wiley, New York, 1982), Chap. 8.

${ }^{33}$ A. Link, K. Bitzer, W. Limmer, R. Sauer, C. Kirchner, V. Schwegler, M. Kamp, D. G. Ebling, and K. W. Benz, J. Appl. Phys. 86, 6256 (1999).

${ }^{34}$ S. Miyazaki, J. Vac. Sci. Technol. B 19, 2212 (2001).

${ }^{35}$ J. R. Waldrop and R. W. Grant, Appl. Phys. Lett. 68, 2879 (1996).

${ }^{36}$ S. W. King, C. Ronning, R. F. Davis, M. C. Benjamin, and R. J. Nemanich, J. Appl. Phys. 84, 2086 (1998).

${ }^{37}$ K. Kunihiro, K. Kasahara, Y. Takahashi, and Y. Ohno, Jpn. J. Appl. Phys., Part 1 39, 2431 (2000).

${ }^{38}$ H. Hasegawa and S. Oyama, J. Vac. Sci. Technol. B 20, 1647 (2002).

${ }^{39}$ H. Hasegawa, S. Ootomo, T. Inagaki, and T. Hashizume, J. Vac. Sci. Technol. B, these proceedings. 